\title{
An Improved Particle Swarm Optimization for Induction Motor Parameter Determination
}

\author{
V.P. Sakthivel \\ Lecturer \\ Department of Electrical Engineering \\ Annamalai University \\ Chidambaram, India
}

\author{
R. Bhuvaneswari \\ BOYSCAST FELLOW \\ Center for Advanced Power Systems \\ Florida State University \\ Tallahassee, USA
}

\author{
S. Subramanian \\ Professor \\ Department of Electrical Engineering \\ Annamalai University \\ Chidambaram, India
}

\begin{abstract}
This paper presents a novel and efficient method to estimate the equivalent circuit parameters of three-phase induction motor from its manufacturer data for steady state analysis using improved particle swarm optimization (IPSO). The IPSO integrates the particle swarm optimization (PSO) with the chaotic sequences. The optimization problem is based on minimizing the error between the computed performance of the equivalent circuit and the manufacturer data. The application of chaotic sequences in PSO is an efficient strategy to improve the global searching capability and escape from local minima. The feasibility of the proposed method is demonstrated for two test motors, and the test results are compared with the simple PSO and classical parameter estimation methods. The simulation results show that the proposed method is capable of obtaining higher quality solutions.
\end{abstract}

\section{General Terms}

Algorithms, Performance, Experimentation, Verification.

\section{Keywords}

Chaotic sequences, Improved Particle Swarm Optimization, Induction Motor, Parameter Estimation, Particle Swarm Optimization.

\section{INTRODUCTION}

Induction machines are extensively applied in all sectors due to their low price and ruggedness. The presence or absence of a large induction machine or a combination of machines in power systems plays a significant role in transient stability or security assessment. Accurate machine parameters are essential for systems behavior prediction. Machine parameters are also crucial in industrial system studies. These parameters are generally determined via the classical no-load and locked rotor tests [1]. However these approaches cannot be implemented easily. Besides, the locked-rotor test requires that the shaft of the motor be locked. Classical approach with linear square has been implemented to identify machine parameters [2], [3]. The linear parameter estimation techniques have been used to determine the rotor resistance, rotor self-inductance and the stator leakage inductance of a three phase induction machine. The problem has also been solved with more sophisticated approach for non linear system identification [4]. In [5], a very complete survey on various approaches to machine parameter estimation has been presented.
A very simple method for determining squirrel cage induction motor parameters and problems in the determination of parameters with two methods proposed in IEEE standard 112 was discussed [6]. Equivalent circuit parameters were calculated from data of three tests: no-load, locked rotor and over load test. The method had the advantage of not requiring torque measurements. The mathematical method for estimating the equivalent circuit parameters of induction machines from the most available performance characteristics was presented [7] [8]. These methods utilizes machine equations to estimate the parameters and then performs sensitivity analysis with respect to the circuit parameters to match the given performance characteristics. A new parameter estimation method for induction motors has been presented [9]. In this method, the double cage induction motor was modeled from manufacturer data such as name plate data and motor performance characteristics.

The evolutionary algorithm [10], genetic algorithm [11] - [15], adaptive GA [16], artificial neural network (ANN) [17] [18] and differential evolution [19] have been used for parameter determination of induction motor.

A particle swarm optimization (PSO) is suggested by Eberhart and Kennedy based on the analogy of swarm of bird and school of fish [20]. The PSO mimics the behavior of individuals in a swarm to maximize the survival of the species. The main advantages of the PSO algorithm are summarized as; simple concept, easy implementation, robustness to control parameters, and computational efficiency when compared with the other heuristic optimization techniques [21]. Chaos, apparently disordered behaviors that is nonetheless deterministic, is a universal phenomenon that occurs in many systems in all areas of science [22]. Recently, chaotic sequences have been adopted instead of random ones and have shown very promising results in many engineering applications [23].

In this paper, a novel approach for solving the parameter estimation problems using an improved particle swarm optimization (IPSO) has been proposed. The application of chaotic sequences in PSO is a useful strategy to improve the global searching capability and prevent the premature convergence to local minima. The proposed IPSO is applied to estimate the equivalent circuit parameters of two sample motors in order to demonstrate the performance of the proposed algorithm. 


\section{FORMULATION OF PARAMETER DETERMINATION}

Parameter determination of three-phase induction motors is formulated as an optimization problem. The inputs required for this method are the nameplate data, torque-slip, current-slip and power factor-slip characteristics. The objective is to find a equivalent circuit parameter set which yields a computed performance of the motor with minimal normalized square error when compared to the manufacturer data. It can be formulated mathematically with an objective function and three constraints.

$$
\mathrm{F}(\mathrm{x})=\sum_{\mathrm{i}=1}^{\mathrm{n}_{\mathrm{I}}} \frac{\Delta \mathrm{I}^{2}\left(\mathrm{~S}_{\mathrm{i}}\right)}{\mathrm{n}_{\mathrm{I}}}+\sum_{\mathrm{i}=1}^{\mathrm{n}_{\mathrm{pf}}} \frac{\Delta \mathrm{pf}^{2}\left(\mathrm{~S}_{\mathrm{i}}\right)}{\mathrm{n}_{\mathrm{pf}}}+\sum_{\mathrm{i}=1}^{\mathrm{n}_{\mathrm{T}}} \frac{\Delta \mathrm{T}^{2}\left(\mathrm{~S}_{\mathrm{i}}\right)}{\mathrm{n}_{\mathrm{T}}}
$$

Where,

$$
\begin{aligned}
\Delta \mathrm{I}\left(\mathrm{S}_{\mathrm{i}}\right)=\frac{\mathrm{I}_{1}\left(\mathrm{~S}_{\mathrm{i}}\right)-\mathrm{I}_{\mathrm{mf}}\left(\mathrm{S}_{\mathrm{i}}\right)}{\mathrm{I}_{\mathrm{mf}}\left(\mathrm{S}_{\mathrm{i}}\right)} \quad \mathrm{i}=1 \ldots \ldots \mathrm{n}_{\mathrm{I}} \\
\Delta \mathrm{pf}\left(\mathrm{S}_{\mathrm{i}}\right)=\frac{\mathrm{pf}\left(\mathrm{S}_{\mathrm{i}}\right)-\mathrm{pf}_{\mathrm{mf}}\left(\mathrm{S}_{\mathrm{i}}\right)}{\mathrm{pf}_{\mathrm{mf}}\left(\mathrm{S}_{\mathrm{i}}\right)} \quad \mathrm{i}=1 \ldots \ldots \mathrm{n}_{\mathrm{pf}} \\
\Delta \mathrm{T}\left(\mathrm{S}_{\mathrm{i}}\right)=\frac{\mathrm{T}\left(\mathrm{S}_{\mathrm{i}}\right)-\mathrm{T}_{\mathrm{mf}}\left(\mathrm{S}_{\mathrm{i}}\right)}{\mathrm{T}_{\mathrm{mf}}\left(\mathrm{S}_{\mathrm{i}}\right)} \quad \mathrm{i}=1 \ldots \mathrm{n}_{\mathrm{T}}
\end{aligned}
$$

m.f Manufacturer data

$\mathrm{S}_{\mathrm{i}} \quad$ discrete values for the induction motor slip $\mathrm{n}_{\mathrm{I}}, \mathrm{n}_{\mathrm{pf}}, \mathrm{n}_{\mathrm{T}}$ number of data points available for current, powerfactor and torque respectively.

\subsection{Minimum and Maximum Parameter Limits}

Each parameter should be laid between minimum and maximum limits. The corresponding inequality constraints for each machine parameter are

$\mathrm{X}_{\mathrm{i}, \min } \leq \mathrm{X}_{\mathrm{i}} \leq \mathrm{X}_{\mathrm{i}, \max }$

Where $\mathrm{X}_{i}, \min$ and $\mathrm{X}_{i, \max }$, are the minimum and maximum value of parameter $i$, respectively.

\subsection{Efficiency Balance Equation}

For efficiency balance, an equality constraint should be satisfied. The calculated full load efficiency should be the same as the manufacturer full load efficiency.

$$
\mathrm{P}_{\mathrm{FL}}-\frac{\left(\mathrm{I}_{\mathrm{FL}}^{2} \mathrm{R}_{1}+\mathrm{I}_{{ }_{\mathrm{FL}}}^{2} \mathrm{R}_{2}+\mathrm{P}_{\mathrm{rot}}\right)}{\mathrm{P}_{\mathrm{FL}}}=\eta_{\mathrm{FL}}
$$

Where $\mathrm{P}_{\mathrm{FL}}$ and $\mathrm{P}_{\text {rot }}$ are the rated power and rotational losses respectively.

\subsection{Maximum Torque Constraint}

$$
\mathrm{T}_{\max . \mathrm{mf}}-\mathrm{T}_{\max (\mathrm{X})} \leq 5 \%
$$

Where $\mathrm{T}$ max.m.f and $\mathrm{T} \max (\mathrm{X})$ are the manufacturer and the estimated maximum torque respectively.

\section{OPTIMIZATION METHODOLOGIES FOR PARAMETER DETERMINATION PROBLEMS}

\subsection{Overview of the PSO}

Particle swarm optimization (PSO), first introduced by Kennedy and Eberhart, is one of the heuristic optimization algorithms. A simple PSO maintains a swarm of particles that represent the potential solutions to the problem on hand. The simple PSO consists of a swarm of particles moving in the Ddimensional space of possible problem solutions. Each particle embeds the relevant information regarding the $\mathrm{D}$ decision variables and is associated with a fitness that provides an indication of its performance in the objective space. Each particle $\mathrm{i}$ has a position $\mathrm{X}_{\mathrm{i}}=\left[\mathrm{X}_{\mathrm{i}, 1}, \mathrm{X}_{\mathrm{i}, 2} \ldots \mathrm{X}_{\mathrm{i}, \mathrm{D}}\right]$ and a flight

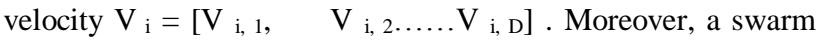
contains each particle $i$ own best position pbest ${ }_{i}=$ (pbest $_{i, 1}$, pbest $_{i, 2}, \ldots \ldots$. pbest $i$, ) found so far and a global best particle position gbest $=\left(\right.$ gbest $_{i}$, gbest $i, \ldots \ldots .$, gbest $\left._{D}\right)$ found among all the particles in the swarm so far.

In essence, the trajectory of each particle is updated according to its own flying experience as well as to that of the best particle in the swarm. The standard PSO algorithm can be described as

$$
\begin{aligned}
& \mathrm{V}_{\mathrm{i}, \mathrm{d}}{ }^{\mathrm{k}+1}=\mathrm{W} \times \mathrm{V}_{\mathrm{i}, \mathrm{d}}{ }^{\mathrm{k}}+\mathrm{C}_{1} \times \operatorname{rand}_{1} \times\left(\text { pbest }_{\mathrm{i}, \mathrm{d}}{ }^{\mathrm{k}}-\mathrm{X}_{\mathrm{i}, \mathrm{d}}{ }^{\mathrm{k}}\right)+ \\
& \mathrm{C}_{2} \times \text { rand }_{2} \times\left(\text { gbest }_{\mathrm{d}}{ }^{\mathrm{k}}-\mathrm{X}_{\mathrm{i}, \mathrm{d}}{ }^{\mathrm{k}}\right) \\
& X_{i, d}{ }^{k+1}=X_{i, d}{ }^{k}+V_{i, d}{ }^{k+1} \\
& \mathrm{i}=1,2 \ldots \ldots \ldots, \mathrm{n} ; \mathrm{d}=1,2 \ldots \ldots \ldots, \mathrm{D}
\end{aligned}
$$

Where $\mathrm{W}$ is a weighting factor; $\mathrm{C}_{1}$ is a cognition acceleration factor; $\mathrm{C}_{2}$ is a social acceleration factor; rand $_{1}$ and $\operatorname{rand}_{2}$ are two random numbers uniformly distributed between 0 and $1 ; \mathrm{V}_{\mathrm{i}, \mathrm{d}}{ }^{\mathrm{k}}$ is the velocity of particle $\mathrm{i}$ at iteration $\mathrm{k} ; \mathrm{X}_{\mathrm{i}, \mathrm{d}}{ }^{\mathrm{k}}$ is the dth dimension position of particle $i$ at iteration $k$; pbest $i, d{ }^{k}$ is the $d$ th dimension of the own best position of particle $i$ until iteration $\mathrm{k}$; gbest $\mathrm{d}^{\mathrm{k}}$ is the dth dimension of the best particle in the swarm at iteration $\mathrm{k}$.The time varying weighting function was introduced in [20] as per which $\mathrm{W}$ is given by

$\mathrm{W}=\mathrm{W}_{\max }-\left(\mathrm{W}_{\max }-\mathrm{W}_{\min }\right) \times$ Iter $/$ Iter $_{\max }$

Where $\mathrm{W}_{\max }$ and $\mathrm{W}_{\min }$ are initial and final weight respectively, Iter is current iteration number and Iter max is maximum iteration number. The model using (4) is called 'inertia weights approach (IWA)'. The inertia weight is employed to control the impact of the previous history of velocities on the current velocity. Thus the parameter W regulates the trade-off between the global and the local exploration abilities of the swarm. A large inertia weight facilitates exploration, while a small one tends to facilitate exploitation. 


\subsection{Improved Particle Swarm Optimization}

One of the simplest dynamic systems evidencing chaotic behavior is the iterator called the logistic map, whose equation is described as follows:

$\mathrm{f}_{\mathrm{k}}=\mu \cdot \mathrm{f}_{\mathrm{k}-1} \cdot\left(1-\mathrm{f}_{\mathrm{k}-1}\right)$

where $\mu$ is a control parameter and has the real value between [0,4]. Despite the apparent simplicity of the equation, the solution exhibits a rich variety of behaviors. The behavior of the system represented by equation (5) is greatly changed with the variation of $\mu$. The value of $\mu$ determines whether ' $\mathrm{f}$ ' stabilizes at a constant size, oscillates between a limited sequence of sizes, or behaves chaotically in an unpredictable pattern. And also the behavior of the system is sensitive to initial value of ' $\mathrm{f}$ ' [22]. Equation (5) is deterministic, displaying chaotic dynamics when $\mu=4.0$ and $\mathrm{f}_{0} \notin \theta_{\text {s }} 0.25,0.50,0.75,1.0$.

In this paper, the new weight is defined as multiplying equation (4) by equation (5) in order to improve the global searching capability as follows:

Wnew $=\mathrm{W} \times \mathrm{f}$

Whereas, the conventional weight decreases monotonously from $\mathrm{W}_{\max }$ to $\mathrm{W}_{\min }$, the proposed new weight decreases and oscillates simultaneously for total iteration as shown in Figure 1.

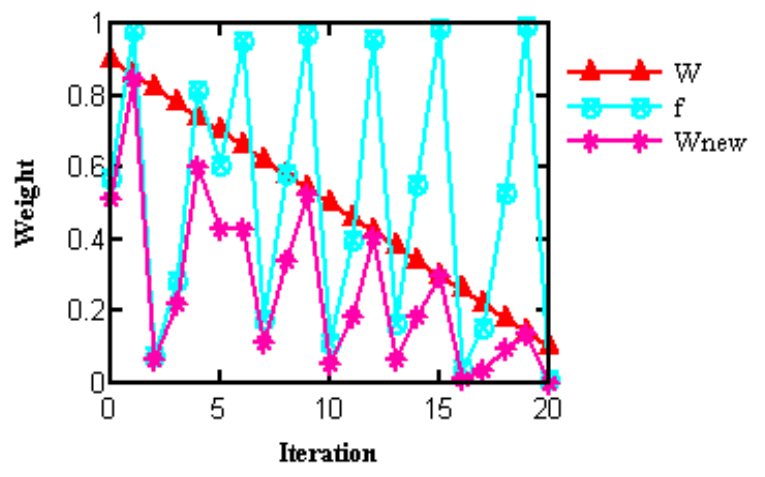

Figure 1. Comparison of weights by each approach

\section{IMPLEMENTATION OF IPSO ALGORITHM FOR PARAMETER DETERMINATION PROBLEMS}

In this section, the implementation of IPSO algorithm for parameter determination problem is described. The proposed IPSO algorithm not only improves the standard PSO algorithm but also adds new strategy in order to find the global solution better than PSO algorithm by applying the chaotic sequences for weight parameter. The proposed algorithm can be summarized as follows:
Step 1: Get the manufacturer data of the induction motor.

Step 2: Initialize parameters $\mathrm{W}_{\max }, \mathrm{W}_{\min }, \mathrm{C}_{1}, \mathrm{C}_{2}$ and Iter Imax $_{\text {. }}$

Step 3: Generate intial population of $\mathrm{N}$ particles with random positions and velocities.

Step 4: Calculate fitness: Evaluate the fitness value of current particle using objective function (1).

Step 5: Update personal best: Compare the fitness value of each particle with its pbests. If the current value is better than pbest, then set pbest value to the current value.

Step 6: Update global best : Compare the fitness value of each particle with gbest. If the current value is better than gbest, set gbest to the current particle's value.

Step 7: Update chaotic weight: Calculate weight Wnew ${ }^{\mathrm{k}+1}$ using equation (6).

Step 8: Updatevelocities: Calculate velocities $\mathrm{V}^{\mathrm{k}+1}$ using equation (6).

Step 9: Update positions: Calculate positions $\mathrm{X}^{\mathrm{k}+1}$ using equation (3).

Step 10: Return to step (4) until the current iteration reaches the maximum iteration number.

Step 11: Output the optimal solution in the last iteration.

\section{RESULTS AND DISCUSSIONS}

To verify the feasibility of the proposed IPSO method, two sample motors were tested and the results are compared with the simple PSO and the classical determination methods [1]. Some parameters must be assigned before IPSO is used to solve the parameter estimation problem as follows: Population size $=$ 20; initial inertia weight $\mathrm{w}_{\max }=0.9$; final inertia weight $\mathrm{w}_{\text {min }}$ $=0.1$; acceleration factor $\mathrm{C}_{1}=\mathrm{C}_{2}=1.5$; maximum iteration Iter $_{\max }=50$; control parameter of chaotic sequences $\mu=4.0$ and the initial value of ' $\mathrm{f}$ ' is a random value between $[0,1]$ except for $(0,0.25,0.5,0.75$, and 1$)$.

The nameplate data of the sample motors are given in Table 1 . The equivalent circuit parameters obtained from the IPSO, PSO and classical methods are reported in Table 2 for the two test motors. The torque-slip and current-slip characteristics were obtained from the parameters available in Table 2 and shown in Figures 2 and 3. It should be noticed that the curves generated by the proposed IPSO method are closer to the manufacturer data than the other methods.

Table 1. Name plate data of the test machines

\begin{tabular}{|c|c|c|}
\hline Specifications & Motor 1 & Motor 2 \\
\hline Capacity & $5 \mathrm{HP}$ & $40 \mathrm{HP}$ \\
\hline Voltage & $400 \mathrm{~V}$ & $400 \mathrm{~V}$ \\
\hline Current & $8 \mathrm{~A}$ & $45 \mathrm{~A}$ \\
\hline Frequency & $50 \mathrm{~Hz}$ & $50 \mathrm{~Hz}$ \\
\hline No. of Poles & 4 & 4 \\
\hline Full load slip & 0.07 & 0.09 \\
\hline Full load torque & $25 \mathrm{Nm}$ & $190 \mathrm{Nm}$ \\
\hline Full load efficiency & $88 \%$ & $90 \%$ \\
\hline
\end{tabular}


Table 2. Summary of parameter estimation results

\begin{tabular}{|c|c|c|c|c|c|c|}
\hline \multirow{2}{*}{ Parameters } & \multicolumn{3}{|c|}{ Motor 1 } & \multicolumn{3}{c|}{ Motor 2 } \\
\cline { 2 - 7 } & Classical & PSO & IPSO & Classical & \multicolumn{2}{c|}{ PSO IPSO } \\
\hline $\mathrm{R}_{1}$ & 8.0 & 1.88 & 2.34 & 0.015 & 0.022 & 0.025 \\
\hline $\mathrm{R}_{2}$ & 5.27 & 5.9 & 5.77 & 0.44 & 0.454 & 0.45 \\
\hline $\mathrm{X}_{1}, \mathrm{X}_{2}$ & 14.81 & 15.46 & 15.4 & 0.58 & 0.59 & 0.59 \\
\hline $\mathrm{X}_{\mathrm{m}}$ & 409.6 & 287 & 309 & 11.57 & 12.27 & 10.9 \\
\hline
\end{tabular}

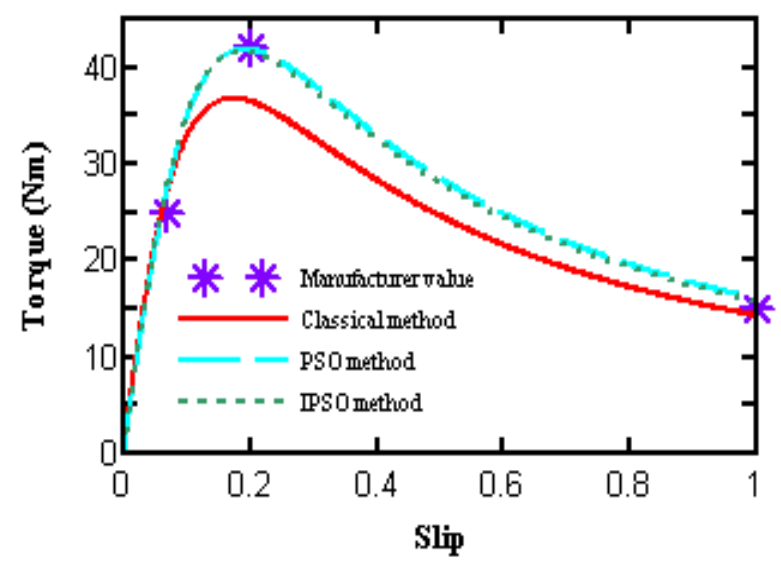

(a)

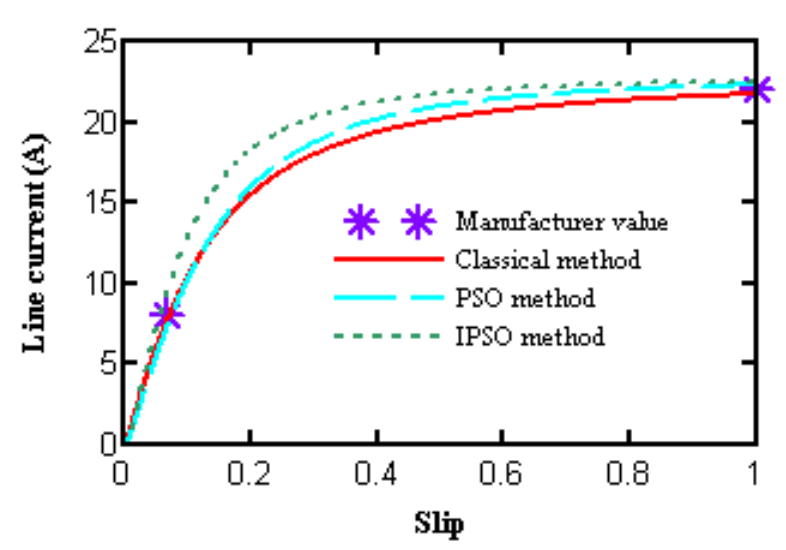

(b)

Figure 2. Performances curves of motor 1 obtained from PSO, IPSO and classical methods
(a) Torque versus slip curve
(b) Current versus slip curve

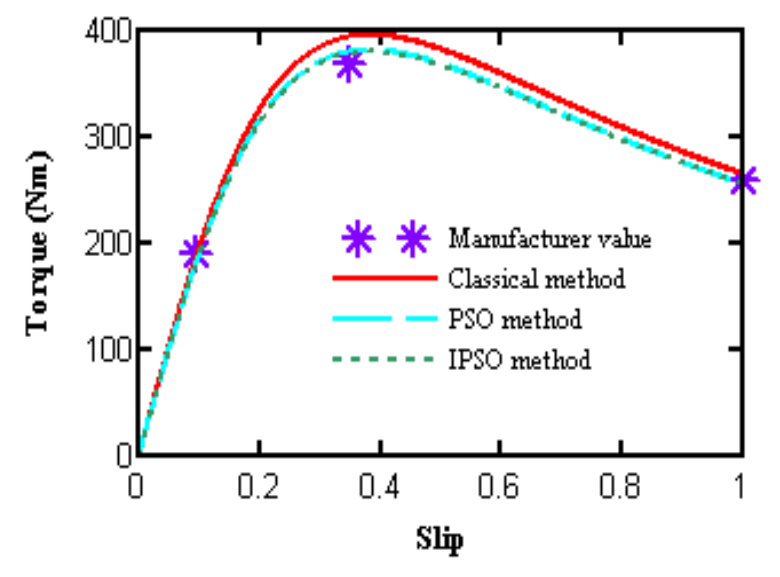

(a)

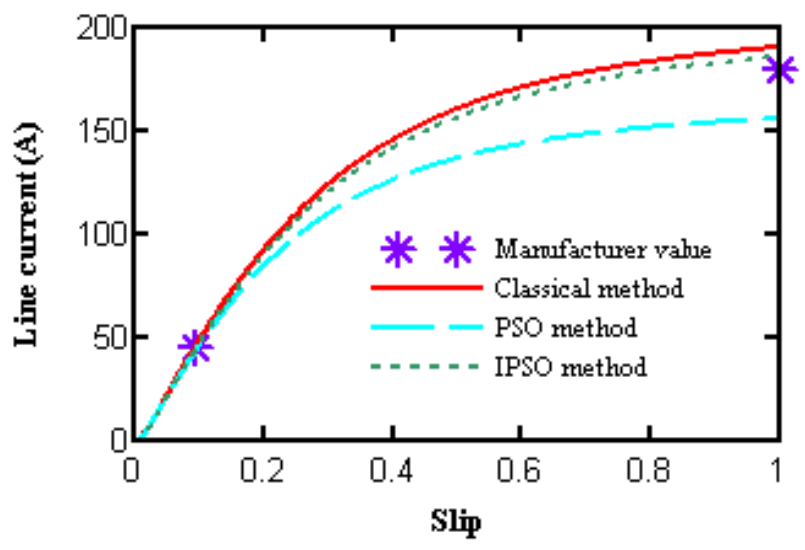

(b)

Figure 3. Performances curves of motor 2 obtained from PSO, IPSO and classical methods
(c) Torque versus slip curve
(d) Current versus slip curve 
Table 3. Comparison of classical, PSO and IPSO results with manufacturer data for motor 1

\begin{tabular}{|c|c|c|c|c|c|c|c|}
\hline \multirow[t]{2}{*}{ Characteristic } & \multirow{2}{*}{$\begin{array}{l}\text { Manufacturer } \\
\text { data }\end{array}$} & \multicolumn{2}{|c|}{ Classical } & \multicolumn{2}{|c|}{ PSO } & \multicolumn{2}{|c|}{ IPSO } \\
\hline & & $\begin{array}{l}\text { Estimated } \\
\text { data }\end{array}$ & Error $(\%)$ & $\begin{array}{l}\text { Estimated } \\
\text { data }\end{array}$ & Error (\%) & $\begin{array}{l}\text { Estimated } \\
\text { data }\end{array}$ & Error (\%) \\
\hline Starting torque $(\mathrm{Nm})$ & 15 & 14.25 & 5 & 16.01 & -6.74 & 15.76 & -5.06 \\
\hline Maximumtorque (Nm) & 42 & 36.46 & 13.18 & 41.84 & 0.38 & 41.63 & 0.89 \\
\hline Full load torque (Nm) & 25 & 27.415 & -9.66 & 27.635 & -10.5 & 27.11 & -8.45 \\
\hline Full load efficiency( \%) & 88 & 83.22 & 5.44 & 90.57 & -2.93 & 90 & -2.27 \\
\hline
\end{tabular}

Table 4. Comparison of classical, PSO and IPSO results with manufacturer data for motor 2

\begin{tabular}{|c|c|c|c|c|c|c|c|}
\hline \multirow[t]{2}{*}{ Characteristic } & \multirow{2}{*}{$\begin{array}{l}\text { Manufacturer } \\
\text { data }\end{array}$} & \multicolumn{2}{|c|}{ Classical } & \multicolumn{2}{|c|}{ PSO } & \multicolumn{2}{|c|}{ IPSO } \\
\hline & & $\begin{array}{l}\text { Estimated } \\
\text { data }\end{array}$ & Error $(\%)$ & $\begin{array}{l}\text { Estimated } \\
\text { data }\end{array}$ & Error (\%) & $\begin{array}{l}\text { Estimated } \\
\text { data }\end{array}$ & Error $(\%)$ \\
\hline Starting torque $(\mathrm{Nm})$ & 260 & 265.24 & -2.01 & 255.68 & 1.66 & 255.93 & 1.56 \\
\hline Maximumtorque (Nm) & 370 & 394.71 & -6.7 & 380.48 & -2.83 & 379.02 & -2.44 \\
\hline Full load torque $(\mathrm{Nm})$ & 190 & 178.17 & 6.22 & 172.6 & 9.16 & 181.89 & 4.2 \\
\hline Full load efficiency( \%) & 90 & 90.65 & -0.72 & 90.5 & -0.55 & 90.4 & -0.45 \\
\hline
\end{tabular}

Table 5. Comparison of results for 20 runs of PSO and IPSO methods

\begin{tabular}{|c|c|c|c|c|}
\hline \multirow{2}{*}{ Values } & \multicolumn{2}{|c|}{ Motor 1 } & \multicolumn{2}{c|}{ Motor 2 } \\
\cline { 2 - 5 } & PSO & IPSO & PSO & IPSO \\
\hline Best & 0.0186 & 0.01789 & 0.00247 & 0.00236 \\
\hline Worst & 0.0285 & 0.0239 & 0.0036 & 0.00275 \\
\hline Deviation (\%) & 53 & 34 & 45.75 & 20.8 \\
\hline
\end{tabular}

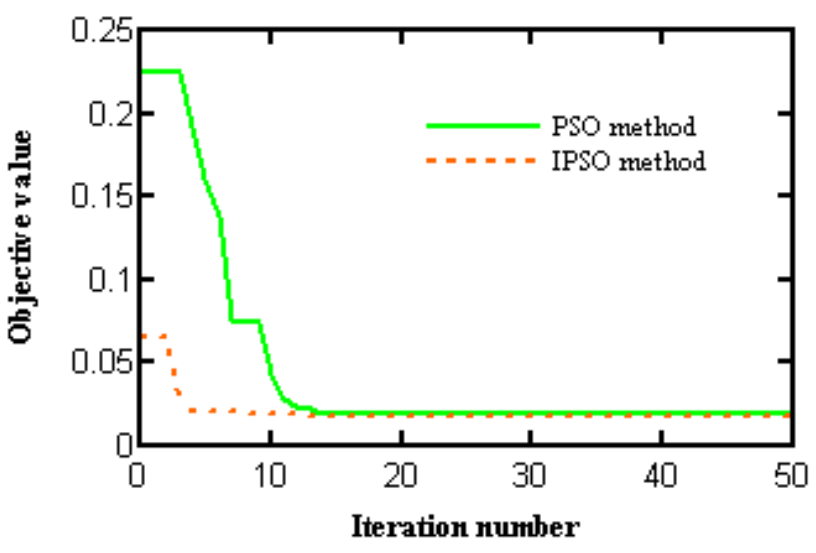

Figure 4. Convergence characteristic for PSO and IPSO methods of motor 1
In order to quantify the comparison between IPSO and other methods, the error is computed for each characteristic of the test motors.

The error (e) is computed as follows:

$$
\mathrm{e}(\%)=\frac{\mathrm{X}_{\mathrm{m}}-\mathrm{X}_{\mathrm{e}}}{\mathrm{X}_{\mathrm{m}}} \times 100
$$

Where, $X_{m}$ and $X_{e}$ are manufacturer and estimated data of performance characteristic $X$. The error in the performance characteristics of the two sample motors obtained from the various methods are given in Tables 3 and 4. It shows that, the IPSO method has produced lesser error than the PSO and the classical methods. It should be emphasized that the distinct achievement of the present work is to avoid the need of performing lab tests in order to obtain a parameter set that will acceptably match the performance of the induction motor over a relatively wide range of operating conditions.

\subsection{Comparison of Two Methods}

\subsubsection{Solution quality}

As seen in Table 5, the IPSO method can obtain lower normalized square error than the PSO method, thus resulting in the higher quality solution. Moreover, through 20 trials, the IPSO method yields smaller percentage deviation of evaluation values than the PSO method. 


\subsubsection{Convergence characteristic}

Figure 4 shows convergence characteristic for the sample motor 1 by IPSO and PSO methods. As it can be seen, the two methods have rapid convergence characteristic. However, because the PSO brings premature convergence, its average squared error is larger than IPSO method. Thus the proposed IPSO method performs better convergence speed than the PSO method, and the simulation results show that the IPSO outperforms PSO.

\section{CONCLUSION}

This paper presents a novel approach for solving the parameter determination problems from the manufacturer data based on the improved particle swarm optimization (IPSO) algorithm. The IPSO uses chaotic sequences for weight parameter to improve the global searching ability and escape from local minima. The IPSO method has been tested on two sample motors and the results were compared with that obtained using the PSO and classical methods. It has produced better results than the PSO method and the solutions obtained have superior solution quality and good convergence characteristics.

\section{ACKNOWLEDGMENT}

The authors thank the authorities of Annamalai University for providing necessary facilities.

\section{REFERENCES}

[1] Say, M.G. 1983. Alternating Current Machines, Pitman.

[2] Koubaa, Y. 2004. Recursive Identification of Induction Motor Parameters. Journal of Simulation Modeling Practice and Theory. 12, 5, 363-381.

[3] Stephan, J., Bodson, M., and Chiasson, J. 1994. Real Time Estimation of Induction Motor Parameters. IEEE Trans. Industrial Applications. 30, 3, 746-759.

[4] Wang, K., Chiasson, J., Bodson, M., and Tolbert, L.M. 2005. A Nonlinear Least Squares Approach for Identification of The Induction Motor Parameters. IEEE Trans. Automatic Control. 50, 10, 1622-1628.

[5] Toliyat, H.A., Levi, E., and Raina, M. 2003. A Review of RFO Induction Motor Parameter Estimation Techniques. IEEE Trans. Energy Conversion. 18, 3, 271283.

[6] Pedra, J., and Sainz, L. 2006. Parameter Estimation of Squirrel-Cage Induction Motors without Torque Measurements. IEE Proc. Electric Power Applications. 153, 2, 263-269.

[7] Ansuj, S., Shokooh, F., and Schinzinger, R. 1989. Parameter Estimation for Induction Machines Based on Sensitivity Analysis. IEEE Trans. Industry Applications. 25, 6, 1035-1040.

[8] Pedra, J., and Corcoles, F. 2004. Estimation of Induction Motor Double-Cage Model Parameters from Manufacturer Data. IEEE. Trans. Energy Conversion, 19, 2 .
[9] Lindenmeyer, D., Dommel, H.W., Moshref, A., and Kundur, P. 2001. An Induction Motor Parameter Estimation Method. Electrical Power and Energy Systems. 23, 251-262.

[10] Nangsue, P., Pillay, P., and Conry, S. 1999. Evolutionary Algorithms for Induction Motor Parameter Determination. IEEE. Trans. Energy Conversion. 14, 3, 447-453.

[11] Bishop, R.R., and Richards, G.G. 1990. Identifying Induction Machine Parameters Using a Genetic Optimization Algorithm. Proceedings. Southeastcon IEEE. 2, 476-479.

[12] Rahimpour, E., Rashtchi, V., and Pesaran, M. 2007. Parameter Identification of Deep-Bar Induction Motors Using Genetic Algorithm. Electrical Engineering. 89, 547-552.

[13] Huang, K.S., Kent, W., Wu, Q.H., and Turner, D.R. 2001. Parameter Identification for Induction Motors Using Genetic Algorithm with Improved Mathematical Model. Electric Power Components and Systems. 29, 3, 247-258.

[14] Nollan, R., Pillay, P., and Haque, T. 1994. Application of Genetic Algorithms to Motor Parameter Determination. Proc. Of 1994 IEEE-IAS conference, Denvar. 47-54.

[15] Orlowska Kowalska, T., Lis, J., and Szabat, K. 2006. Identification of the Induction Motor Parameters using Soft Computing Methods. COMPEL, 25, 1, 181-192.

[16] Abdelhadi, B., Benoudjit, A., and Nait Said, N. 2004. Identification of Induction Machine Parameters Using an Adaptive Genetic Algorithm. Electric Power Components and Systems. 32, 767-784.

[17] Michael, T.W., and Ronald, G.H. 1995. Identification and Control of Induction Machines Using Artificial Neural Networks. IEEE Trans. Industry Applications Proc.

[18] Bae, D. 1997. Determination of Induction Motor Parameters by Using Neural Network Based on FEM Results. IEEE Trans. Magnetics, 33, 1924-1927.

[19] Ursem, R.K., and Vadstrup, P. 2003. Parameter Identification of Induction Motors Using Differential Evolution. The 2993 Congress on Evolutionary Computation CEC 03. 2, 790-796.

[20] Kennedy, J., and Eberhart, R.C. 1995. Particle Swarm Optimization. Proc. IEEE Int. Conf. Neural Networks. 4, 1942-48.

[21] Lee, K.Y., and EI-Sharkawi. 2002. Modern Heuristic Optimization Techniques with Applications to Power Systems. IEEE Power Engineering Society (02TP160).

[22] Ying Song, Zengqiang Chen and Zhuzhi Yuan. 2007. New Chaotic PSO Based Neural Network Predictive Control for Non Linear Process. IEEE Transactions on Neural Networks. 18, 2, 595-600.

[23] Cai Jiejin,Ma Xiaoqian, Li xiang and Peng Haipeng. 2007. Chaotic Particle Swarm Optimization for Economic Dispatch Considering the Generator Constraints. Energy Conversion and Management. 48, 645 - 653. 